\title{
Las lenguas indígenas argentinas como objeto de colección. Notas acerca de los estudios lingüísticos de Samuel A. Lafone Quevedo a fines del siglo XIX
}

\author{
por \\ Máximo Farro ${ }^{1}$ \\ CONICET/ Archivo Histórico del Museo de La Plata (UNLP)
}

En este artículo se analizan los trabajos de clasificación de las lenguas indigenas desarrollados por Samuel Alexander Lafone Quevedo hacia fines del siglo XIX, prestando especial atención a su contexto de producción. Para ello se toman en consideración las prácticas de obtención y organización de los datos lingüisticos, las relaciones de cooperación que estableció con corresponsales y las actividades desarrolladas en los espacios institucionales de los que formó parte.

Palabras Clave: Samuel A. Lafone Quevedo (1835-1920); lenguas indigenas; etnografía lingüistica; recolección de datos lingüisticos; redes de corresponsales; mapas étnicolingüísticos.

\section{INTRODUCCIÓN}

En los trabajos referidos a la clasificación de las lenguas indígenas del continente americano producidos durante el último tercio del siglo XIX una de las principales líneas de indagación estuvo relacionada fundamentalmente con la obtención y sistematización de fuentes que habían sido elaboradas a

\footnotetext{
${ }^{1}$ Debo agradecer el juicio crítico, las sugerencias y los comentarios realizados a este trabajo por dos evaluadores anónimos, y por Irina Podgorny, Andrea Pegoraro y José Antonio Pérez Gollán. Los posibles errores u omisiones son de mi entera autoría. Este trabajo fue realizado en el marco de los proyectos PICT 32111 y PIP CONICET 0116 «El comercio de datos y artefactos en la cultura de las ciencias de los Siglos XIX y XX», dirigidos por la Dra. Irina Podgorny.
} 
partir del siglo $\mathrm{XVI}^{2}$. Esta preocupación constante por la obtención de nuevos datos para los estudios comparativos se materializó en ediciones críticas de gramáticas y de vocabularios que fueron originalmente compuestos por misioneros y por funcionarios de la corona española ${ }^{3}$. Una parte importante del trabajo consistió así en la recolección y revisión de datos para hacer descripciones de las estructuras gramaticales y clasificaciones de las lenguas por familias, en detrimento de la reflexión teórica ${ }^{4}$. En contraposición a las líneas de investigación asociadas al campo de las ciencias naturales, que se dedicaron al estudio del lenguaje entendido como fenómeno biológico, los estudios sobre las lenguas americanas fueron circunscriptos dentro del campo de las ciencias históricas conformando una corriente dedicada al establecimiento de una «etnografía lingüística» que tuvo su auge sobre todo en la última década del siglo XIX con los trabajos de Daniel Garrison Brinton (1837-1899) en los Estados Unidos y de Lucien Adam (1833-1919) en Francia5.

Es en estas coordenadas generales donde se pueden ubicar los trabajos que Samuel Alexander Lafone Quevedo (1835-1920) desarrollará a lo largo de la década de 1890 para el Museo de La Plata y para el Instituto Geográfico Argentino, con la publicación de ediciones críticas de manuscritos y «obras raras» referidas a aquellas lenguas indígenas de la América meridional de las que existían abundantes testimonios en el territorio argentino. Residente en la provincia de Catamarca, en el Noroeste de la Argentina, Lafone Quevedo realizó un trabajo de recolección y compilación de fuentes manuscritas en los archivos locales, registró vocabularios a partir de informantes indígenas y relevó información en las bibliotecas y colecciones de manuscritos del general Bartolomé Mitre (1821-1906) y Andrés Lamas (1817-1891) referidos fundamentalmente a las lenguas y dialectos indígenas de aquella región y del Chaco. Con esos materiales comenzó a bosquejar un esquema de clasificación basándose en un rasgo gramatical específico que estaba asociado a una forma particular de aglutinación que para él era propia del continente americano, como son las partículas pronominales y sus formas de articulación tanto con los verbos como con los nombres. La recolección de datos para fundamentar este esquema clasificatorio implicó un riguroso proceso de extracción, registro y organización de los datos a partir de un corpus de manuscritos y de vocabularios impresos con el objeto de convertirlos en series útiles para el trabajo de comparación de las formas de colocación de las partículas pronominales entre

\footnotetext{
2 Auroux y Queixalós, 1984.

3 Torres, 1909: VII-XLIII.

${ }^{4}$ Auroux, 2000: 16-17. Desmet, 1996: 451-452.

${ }^{5}$ Dias y Rupp-Eisenreich, 2000: 293-294.
} 
las distintas lenguas y dialectos. Con la ayuda de un escribiente Lafone Quevedo organizó así una colección con transcripciones de vocabularios formada por cuadernillos donde se ordenaban alfabéticamente las entradas, asentando en una columna los vocablos en idioma indígena y en una columna contigua sus equivalentes en castellano. En relación con esto nos interesa destacar aquí una observación que realizara en 1875 el estudioso norteamericano William Dwight Withney (1827-1894) que se refiere precisamente a esta dimensión material del lenguaje y su relación con las prácticas asociadas al armado de colecciones para los estudios de clasificación y comparación. Mediante su transcripción a un sustrato de papel —afirmaba Withney-, las lenguas podían transformarse en un objeto pasible de ser almacenado, clasificado y estudiado comparativamente a la manera de los especimenes que componen las colecciones de historia natural ${ }^{6}$.

Siguiendo esta idea, en las páginas que siguen se analizan los trabajos de clasificación lingüística desarrollados por Lafone Quevedo hacia fines del siglo XIX prestando especial atención a su contexto de producción. En ese sentido, se describen las prácticas relacionadas con la compulsa de documentos del siglo XVI en los archivos de la provincia de Catamarca que Lafone Quevedo realizara con el objeto de confeccionar una toponimia regional referida a la lengua Cacana que se había hablado en el Noroeste de la Argentina, especialmente en aquella provincia, los valles Calchaquíes y en parte de La Rioja, Santiago del Estero y de San Juan?7. A partir de la década de 1890 Lafone Quevedo se dedicará al estudio comparado de las lenguas y dialectos indígenas de la región del Chaco, entre las que se destacan el Lule, el Vilela y aquellas pertenecientes a las familias Mataco-Mataguaya (Vejoz y Noctén) y Guaycurú (Mbayá, Abipón, Mocoví y Toba) ${ }^{8}$. Se describen en consecuencia las tareas relacionadas con la obtención y organización de los datos lingüísticos para las clasificaciones, el diseño de instrucciones para la recolección de vocabularios indígenas, el montaje de una red de corresponsales y la concepción de un plan editorial para la difusión de una Biblioteca

\footnotetext{
${ }^{6}$ «Une agglomération de sons venant à former un mot est presque autant une entité objective qu'un polype ou qu'un fossile. On peut la déposer sur une feuille de papier, comme une plante dans un herbier, pour l'examiner à loisir». Whitney, 1875: 256.

7 Esta lengua fue conocida también como kaká, caca, chaka, catamarcana, diaguita y calchaquí. Para un estudio detallado sobre la misma véase Nardi, III (Chivilcoy, 1979): 1-33.

${ }^{8}$ El Lule se hablaba en Santiago del Estero, Tucumán y el norte de Salta, y el Vilela (o Chunupí) en Santiago del Estero y el Chaco salteño, ocupando ambas márgenes del río Bermejo. De la familia Mataco-Mataguaya, el Noctén se hablaba en Bolivia y el Vejoz en la región ubicada entre Tartagal y el río Bermejo. Las lenguas de la familia Guaycurú se extendieron a lo largo de los ríos Paraná y Paraguay, desde el Brasil hasta la ciudad de Santa Fé. Bixio, 2001.
} 
de Lingüística. Asimismo, se consideran los apoyos que recibió del Instituto Geográfico Argentino para llevar adelante un proyecto referido a la «geografía histórica» de las lenguas indígenas del territorio argentino, por medio de la publicación sostenida de sus trabajos y la elaboración de mapas étnicolingüísticos donde se integraron visualmente los datos recolectados.

«HARD AT WORKS COPYING OLD PAPERS» ${ }^{9}$

Samuel Alexander Lafone Quevedo era un empresario minero residente en Catamarca, propietario del establecimiento «Pilciao-Las Capillitas» que, junto a «La Constancia» de Adolfo Esteban Carranza (1824-1896), formaba lo que en la época era conocido como el «emporio minero catamarqueño» ${ }^{10}$. Su padre, Samuel Fisher Lafone (1805-1871), pertenecía a una influyente familia de comerciantes oriundos de Liverpool, dedicada desde inicios del siglo XIX al tráfico comercial entre el Río de la Plata e Inglaterra, con especial énfasis en las actividades de saladería, el curtido de cueros, la navegación a vapor y la explotación ganadera en la campaña bonaerense, Montevideo y las Islas Malvinas. Como producto de estas actividades Fisher Lafone había desarrollado vínculos con los más importantes círculos de negocios y sociabilidad porteños desde al menos 1830, casándose con María Quevedo y Alsina, hija de un destacado comerciante español ${ }^{11}$.

Enviado por su familia a Inglaterra, entre 1848 y 1857 Samuel Alexander estudió primero en Liverpool y después en el Saint John's College, de la Cambridge University donde obtuvo el título de bachiller en humanidades (Magister Artium). De regreso al Río de la Plata en 1860, se instaló en la región de Santa María (Catamarca) como administrador del establecimiento minero «Las Capillitas» que había sido adquirido por su padre unos años antes con el fin de explotar mineral de cobre en gran escala y, en menor medida, dedicarse a la extracción de oro y plata. Entre 1860 y 1880, esto es, en el período de producción máxima de las minas, Lafone Quevedo amasó una considerable fortuna ${ }^{12}$. Algunos años más tarde los ingenios de fundición fueron trasladados a «Pilciao», un algarrobal situado a veinticinco kilómetros al sur de la capital departamental de Andalgalá, localidad considerada en ese momento como «El Dorado de América del Sur» donde, según el testimonio de viajeros británicos,

\footnotetext{
9 Entrada del «Diario» de Lafone Quevedo para el año 1884, citada en Furlong, 1964: 97.

${ }^{10}$ Hünicken, 1894.

${ }^{11}$ Canclini, 48 (Buenos Aires, 1999): 123-161.

12 Hünicken, 1894. Furlong, 1964.
} 
Lafone llevaba la vida de un auténtico «lord of the manor» ${ }^{13}$. En los ratos de ocio que le dejaba la administración de los negocios, Samuel se dedicaba a la lectura de obras referidas a la historia americana y, a la manera de los anticuarios que había conocido durante sus años de formación en Inglaterra, recolectaba piezas de arqueología, visitaba «antiguallas» (ruinas), compulsaba información en los archivos provinciales y recorría los valles «con el Lozano ${ }^{14}$ en la mano», registrando testimonios y vocabularios de los habitantes locales con el objeto de estudiar los cambios históricos ocurridos en la toponimia de Catamarca y Tucumán.

Hacia mediados de la década de 1860, Samuel Alexander se relacionó con los círculos sociales que gravitaban alrededor de la figura del general Bartolomé Mitre, un conocido de la familia desde los años de exilio en Montevideo, con quien aquel compartía su afición por el estudio de las lenguas americanas. Así, por intermedio de Ángel Justiniano Carranza (1834-1899) — hermano del empresario minero Adolfo-, Samuel se vinculó al Instituto Bonaerense de Numismática y Antigüedades (1872) y, desde 1876, formará parte de la Sociedad Científica Argentina como socio corresponsal en Catamarca. ${ }^{15}$ En sus frecuentes viajes a la ciudad de Buenos Aires para atender los asuntos de los negocios familiares, Samuel visitaba asiduamente a Mitre, quien puso a su disposición su importante colección de manuscritos y libros referidos a las lenguas del continente americano y lo presentó a otros estudiosos de «temas americanos» como Andrés Lamas y Manuel Trelles (1821-1893), con quienes había formado el Instituto Histórico y Geográfico del Río de la Plata entre 1854 y 1859. Estos últimos participaban de una amplia red de intercambio de documentos, libros y datos que estaba formada por algunos de los bibliófilos y coleccionistas de documentos más importantes del Río de la Plata y de Chile. Como ha señalado Buchbinder, con el correr del tiempo la colaboración entre los miembros de esa red se tradujo en la localización, compulsa y trascripción de documentos en los archivos públicos y privados de sus respectivos países $\mathrm{o}$ en el extranjero, y en su posterior intercambio ${ }^{16}$.

Lafone Quevedo comenzará a compulsar documentos en el Archivo de la provincia de Catamarca y en los repositorios particulares de algunas de las familias más antiguas de la región, motivado principalmente por un problema

13 Ross Johnson, 1868. White, 1881-1882.

${ }^{14}$ Lafone Quevedo, 1888. La referencia es a la obra del padre Pedro Lozano Historia de la conquista del Paraguay, Río de la Plata y Tucumán, editada por Andrés Lamas en cinco volúmenes impresos en la Imprenta Popular de Buenos Aires entre 1873 y 1875.

15 Acerca de las actividades referidas a la clasificación de medallas y monedas del Instituto Bonaerense de Numismática y Antigüedades véase Aufiero, 212 (Toulouse, 2010): 159-182.

${ }_{16}$ Buchbinder, 13 (Buenos Aires, 1996): 59-82. 
legal, muy extendido desde antiguo en las provincias del norte, referido a los títulos de propiedad de la tierra ${ }^{17}$. La información contenida en esos documentos probatorios era importante para el desarrollo de las actividades empresarias de Lafone Quevedo, caracterizadas por una creciente diversificación basada en el uso intensivo de la tierra y el agua ${ }^{18}$, y por una importante expansión territorial por los valles del sudoeste y del noreste de Catamarca. En numerosas ocasiones actuó como condómino asociado con los habitantes indígenas, a quienes utilizaría posteriormente como informantes en sus estudios sobre las lenguas habladas en ese momento en la región.

Otro problema asociado a la determinación de los títulos de propiedad de estas «mercedes» o «heredades» de la región del Noroeste, y que motivaba también la compulsa de los archivos locales, fue la determinación de la extensión de las mismas ya que con el correr del tiempo y los cambios en los límites entre las provincias de Catamarca, Tucumán y Salta, las propiedades quedaron bajo distintas jurisdicciones. En ese contexto, caracterizado por una creciente cantidad de pleitos que debía resolver la justicia local, los acervos de familias de antiguo abolengo en la región eran fundamentales, ya que contenían copias de documentos que no era posible localizar ya en los archivos provinciales:

La historia de Tucumán puede decirse que se halla escrita en los archivos de papeles que en mucha parte existen en poder de los descendientes de las familias conquistadoras ó de sus representantes. Mucho se ha perdido, mucho está trunco, pero creo que aun mucho más es lo que queda, por la sencilla razón de que numerosos papeles se copiaban una y más veces con cualquier pretesto, sin contar para nada los originales en los archivos públicos; pero cae de su suerte que no todos pueden tener la suerte de conseguir el permiso para hacer registros de papeles de familia como que estas recelan que pudiera alguna vez irrogárseles algún prejuicio. [...] Me consta que todas las grandes y ricas familias de la era de la conquista y aún de mucho después, hacían levantar informaciones judiciales para hacer constar los servicios prestados por sus antepasados y en esas informaciones están consignados infinitos hechos que tienen relación con nuestra historia ${ }^{19}$.

Revisando esas «arcas manuscritóvoras de las familias del país» ${ }^{20}$, Lafone Quevedo descubrió documentos, o copias de ellos, que databan del siglo XVII que contenían información fundamental para determinar los «derroteros» de las primeras expediciones de los españoles en la región, lo que permitía establecer los asientos originales de pueblos y ciudades que, como Londres, Cañete y

\footnotetext{
${ }^{17}$ Véase al respecto Mata de López, 2005.

18 Acerca de este tema, véase Zubrzycki, 2005.

19 Lafone Quevedo, 1888: 15.

${ }^{20}$ Ibidem: vi.
} 
Córdoba de Calchaquí, habían estado administrativamente circunscriptos a la antigua jurisdicción del Tucumán. También pudo copiar documentos producidos en la segunda mitad del siglo XVIII, como los «mapas de deslinde» y los «empadronamientos de indios tributarios» a partir de los cuales se podían verificar los cambios acaecidos en la toponimia local. Con el mismo objetivo de obtener datos y documentos, por intermedio del clero local entró en relación con los curas vicarios residentes en distintas localidades del interior de la provincia $^{21}$. También tomó contacto con miembros del Convento de la Orden Seráfica en Catamarca, de cuyas redes sacará provecho posteriormente para la recolección de información, sobre todo en forma de manuscritos referidos a las lenguas americanas conservados en sus archivos, y datos acerca de las poblaciones indígenas que habitaban en ese momento en las regiones bajo influencia de la orden, en los territorios de Salta, Jujuy, el Chaco y Bolivia ${ }^{22}$.

Para agilizar el trabajo de compilación de materiales Lafone Quevedo contrató los servicios de un asistente quien, a la manera de los amanuenses, recorría los archivos transcribiendo íntegramente los documentos en cuadernillos y cuartillas que remitía en paquetes al fundo de aquel, en Pilciao. A partir de este incipiente corpus documental Lafone Quevedo realizó su primer trabajo de investigación referido a la cuestión de las distintas fundaciones y emplazamientos del antiguo Tucumán, cuyos resultados aparecieron en forma de cartas publicadas entre 1882 y 1883 en las páginas del periódico El Creyente de la ciudad de Catamarca. A partir de la exégesis de la obra del padre Lozano y de su confrontación con la colección de transcripciones de documentos que le enviaba su asistente, y con lo datos que recolectó personalmente, polemizó con Paul-François Groussac (1848-1929) quien había publicado un estudio acerca de aquel tema ${ }^{23}$. Con el apoyo de Mitre Lafone Quevedo continuará publicando estas cartas en el diario La Nación, las que posteriormente compilará y corregirá para publicar el libro Londres y Catamarca (1888) con varios apéndices documentales y un mapa histórico.

Para fundamentar mejor sus opiniones, Lafone Quevedo se dedicó en lo subsiguiente a confeccionar de manera sistemática etimologías compuestas por vocablos de uso local con las que compiló un thesaurus o "Vocabulario Catamarcano». La consiguiente revelación de los cambios a lo largo de los siglos tanto en los nombres de lugare ${ }^{24}$ como en los nombres de los individuos

21 Ibidem: 378.

22 Ibidem: 382.

${ }^{23}$ Groussac, 1882.

${ }^{24}$ Lafone Quevedo consideraba a los nombres de lugar como «mojones de la Historia, Etnología, Filología y muchas otras ciencias más». Lafone Quevedo, III (Buenos Aires, 1890): 144. 
pertenecientes a los distintos grupos indígenas - de lo que daban cabal evidencia los empadronamientos de indios tributarios - lo llevaron a adentrarse en el estudio de las lenguas indígenas de la América meridional de las que, sostenía, se hallaban abundantes testimonios en nuestro país, motivo por el cual las denominó «Lenguas Argentinas» ${ }^{25}$. Se concentró así en el estudio de la «Lengua General del Cuzco» o Quichua y su relación con la lengua Cacana, propia de la región Diaguita, que comprendía las antiguas jurisdicciones de Londres, Rioja, Catamarca y Santiago del Estero, y a la que consideró en un principio como un dialecto de la primera ${ }^{26}$. Para comprobarlo recorrió los valles de Catamarca con una libreta de apuntes o «cartera», donde compiló vocablos en uso de la «lengua del Cuzco» aportados por sus empleados y sus redes de conocidos, como Teresa Hualcumay, o por socios de sus emprendimientos comerciales en distintas localidades, como Magdalena Gómez «famosa médica y que sabe componer quebraduras y zafaduras» quien «con un andar de reina en medio de su pobreza, vecina mía y condómina conmigo en esos derechos de indios de Huaco, me entretuvo mas de tres días dándole salida a casi dos tercios de las voces quíchuas contenidas en la reproducción del diccionario de Holguín por von Tschudi» ${ }^{27}$. En el habla popular Lafone Quevedo registró una serie de lo que dio en llamar «fósiles lingüísticos» ${ }^{28}$ a los que entendía como relictos de lenguas que fueron habladas en la región desde antiguo y que, argumentaba, debían ser rescatados ya que corrían peligro de desaparecer amenazados por los efectos uniformadores que las escuelas primarias estaban comenzando a tener sobre ellos ${ }^{29}$. También halló rastros de vocablos que a su entender eran de origen Araucano ya que contenían la raíz Co- que denota «agua» — que estarían reflejados en los nombres de «lugarejos» o pueblos de Catamarca como Coneta y Conando- que atestiguaban la posible existencia

\footnotetext{
25 «El antiguo virreinato del Río de la Plata, en la importancia y variedad de las lenguas indígenas que encierra en su perímetro, no tiene por qué ceder el primer lugar a región alguna de las tres Américas, sin excluir al mismo México. Por el Este está el Guaraní, por el Oeste el Quichua, por el Sud el Araucano; esto, ya en sí, bastaba para abarcar las tres cuartas partes de nuestra América. Por el Norte, asomaban las lenguas Chiquita y Moja, ésta una cuña metida por el impulso de la raza Caríbica, triángulo étnico-lingüístico cuyo ápice descansa en los Chiquitos y su base en el Orinoco con aspadas en todas direcciones, que alcanzaron a abrazar a las mismas Antillas». Lafone Quevedo, 1898: v.

${ }^{26}$ Lafone Quevedo, 1888: ix-x.

27 Ibidem: 102.

${ }_{28}$ Este concepto fue acuñado por el suizo Adolphe Pictet (1799-1875) para el estudio de las lenguas Indo-Europeas, quien definió una «paleontología lingüística» que, por medio de las reconstrucciones léxicas, permitiría conocer el centro de origen de una lengua y el «estado de civilización» de sus hablantes. Morpurgo Davis, 1998: 175.

${ }^{29}$ Lafone Quevedo, 1898: xiii.
} 
de un tronco lingüístico primordial, que habrían tenido en común las lenguas Quichua y Cacana. Esta prueba lingüística, reforzada con el testimonio de la obra del cronista Fernando de Montesinos, indicaría la presencia de una gran nación pre-incásica que habría ocupado toda la región andina.

Pero fue el hallazgo fortuito de un vocablo en un documento de propiedad particular ${ }^{30}$, lo que le sugirió que la lengua Cacana no sería «un dialecto más o menos corrompido del Quechua», sino una lengua distinta. La recolección de nuevas evidencias referidas a la forma de colocar las partículas pronominales y el ejercicio de tabular los vocablos, separando las raíces que eran indudablemente Quichuas de las que no lo eran, le sugirieron que la lengua Cacana tendría mayores probabilidades de filiación con las lenguas propias de los grupos indígenas de las tierras bajas del Este ${ }^{31}$. Esto fue lo que hizo que orientara sus investigaciones desde la indagación en la toponimia de la región que rodeaba su lugar de residencia, hacia el estudio de los grupos lingüísticos del Chaco.

Es importante destacar aquí que en esos años Lafone Quevedo comenzó a bosquejar un sistema de clasificación de las distintas familias lingüísticas de la América meridional que irá perfeccionando con el correr del tiempo, basándose en un rasgo gramatical específico que estaba asociado a una forma particular de aglutinación, que para él era propia del continente americano, como son las partículas pronominales y sus formas de articulación, tanto con los verbos como con los nombres. En su esquema distinguió así dos «gramáticas matrices»: una formada por el grupo «Brasiliense» o «Atlántico», que se caracterizaba por prefijar las partículas pronominales [ej. «mi-libro»] y otra por el grupo «Andino» o «del Pacífico», que colocaba estas partículas como sufijo [ej. «libro-mi $(o) »]^{32}$. Los distintos dialectos del Guaraní y las lenguas pertenecientes a la familia Moja-Maypure-Aruaca serían ejemplos del primer grupo, que abarcaba geográficamente el espacio comprendido desde «las Antillas y el Orinoco hasta la cuenca del río de la Plata» y desde el Atlántico a

\footnotetext{
${ }^{30}$ Adán Quiroga (1863-1904) un abogado amigo de Lafone que residía en Catamarca ganándose la vida con los pleitos entre particulares sobre los títulos de propiedad, lo invitó a revisar juntos los «viejos papeles de la familia González», donde «ambos encontramos algo de lo que buscábamos; porque los papeles contenían las pruebas que él necesitaba para explicar el fraccionamiento de la Merced de Singuil en siglos atrás; y uno de los linderos resultaba decir así: 'Desde el filo llamado Enjamisajo', y en seguida daba la explicación que esta voz quería decir 'Cabeza mala'. En Catamarca las dos lenguas de los indígenas eran la general (del Cuzco) y la Cacana; y como la tal voz de ninguna manera podía atribuirse a la primera, podía pertenecer a la segunda». Lafone Quevedo, 1898: xiv.

31 Lafone Quevedo, 1888.

${ }^{32}$ Lafone Quevedo, XXIII/8775 (Buenos Aires, 1892a): 1-2.
} 
las faldas de la Cordillera de los Andes. Por su parte, el Quichua, el Aymará y el Araucano «los tres idiomas jefes de los Andes» serían ejemplos del segundo grupo, abarcando la región cordillerana «desde Quito hasta el estrecho de Magallanes». Situadas entre estos grupos «Atlántico» y «Andino», Lafone Quevedo identificó una serie de lenguas y codialectos de «naciones» que formaban lo que denominó «grupo del medio», que al hallarse «encerradas entre la Guaraní, que es prefijadora, y la Quichua, subfijadora» se caracterizaban por valerse de las dos clases de afijos pronominales de relación personal [ej. «mi-libro-yo»] ${ }^{33}$. Este grupo incluía, comenzando desde el norte, a los Caribes y Maypures, a los Chiquitos y finalmente a las «naciones Guaycurúes» formadas por los Mbayas, Lenguas, Payaguaes, Abipones, Mocovíes y Tobas, entre otras ${ }^{34}$. Es precisamente a este grupo de las lenguas del Chaco, caracterizadas por la «hibridación» y la mezcla, al que Lafone Quevedo se dedicará en lo sucesivo a estudiar en profundidad, apoyado en la comparación de las formas de articulación de las partículas pronominales como rasgo clasificatorio principal.

\section{La sección lenguas americanas del Museo de la Plata}

Como hemos señalado en otro lado, Lafone Quevedo había comenzado a colaborar con el Museo de La Plata en 1888 mediante el envío de colecciones de objetos arqueológicos y de cráneos que había hallado en el transcurso de sus numerosas excursiones por el interior de la provincia de Catamarca ${ }^{35}$. En agradecimiento a la cooperación que aquel prestara para el desarrollo de las expediciones del Museo en aquella región, su director Francisco Pascasio Moreno (1852-1919) lo nombró encargado honorario de la «Sección de Arqueología y Lenguas Americanas». Para ello le ofreció un espacio donde publicar sus trabajos y la promesa de que contaría con las colecciones de cráneos de la región Calchaquí clasificadas, cuyos datos podría utilizar posteriormente en las clasificaciones de los grupos indígenas de aquellos valles ${ }^{36}$. De ese modo,

33 Idem.

${ }^{34}$ Lafone Quevedo, XIV (Buenos Aires, 1893): 505-528.

35 Farro, 2009. Acerca del contexto general de la creación de museos en el Río de la Plata en el siglo XIX, véase Podgorny 2009. Podgorny y Lopes 2008. Las familias Lafone-Quevedo y Moreno-Thwaites se conocían desde la década de 1840 cuando el padre de Moreno, Francisco Facundo, participó en distintos negocios con Samuel Fisher Lafone en la plaza comercial de Montevideo.

${ }^{36}$ Lafone Quevedo, IV (Washington DC, 1891): 356-371. Las colecciones de cráneos de la región Calchaquí fueron clasificadas y estudiadas recién en 1896 por Herman F.C. ten Kate, primer encargado de la sección antropológica del Museo de La Plata. Farro, 2009: 137-169. 
podría cotejar los datos de la antropología física con aquellos referidos a la etnografía y la lingüística que ya tenía relevados de los documentos de los archivos, los vocabularios y las obras de los misioneros. Gran parte de su trabajo durante estos años fue la publicación de ediciones críticas de manuscritos y «obras raras» referidas a aquellas lenguas de la América meridional de las que existían abundantes testimonios en el territorio argentino, a las que agrupará por ello bajo el nombre general de «Lenguas Argentinas». A partir de esas obras, en especial de las que se referían al «grupo del medio», se dedicó fundamentalmente a la extracción, sistematización y organización de los datos lingüísticos, esto es, a su reducción a «Arte y Vocabulario».

Estos trabajos fueron muy bien ponderados en la época por estudiosos como Lucien Adam y Daniel Brinton debido a la escrupulosidad, la organización y la presentación metódica de la información consignada en tablas, producto de la compulsa minuciosa entre las fuentes más diversas. En este sentido, nos interesa destacar aquí un aspecto que muy probablemente haya influido en esta habilidad para la organización de los datos, como es la aplicación del conocimiento tácito derivado de las prácticas comerciales que constituyeron su ocupación principal hasta los primeros años del siglo XX. Como hijo primogénito perteneciente a una familia de activos comerciantes británicos y peninsulares, Samuel había sido introducido desde temprano en el mundo de los negocios. Desde el regreso de su estadía de estudio en Cambridge estuvo al frente de la administración de los emprendimientos mineros en Catamarca llevando el movimiento contable cotidiano y manejando las remesas con los bancos de Buenos Aires, Montevideo, Liverpool y Londres de una empresa que con el correr del tiempo aumentó considerablemente su número de empleados, se expandió territorialmente y diversificó sus actividades hacia la agricultura, la ganadería y el comercio de productos de ultramar con Bolivia y el norte de Chile, por medio de la firma Lafone, Franco \& $\mathrm{Co}^{37}$. Señalemos aquí que las convenciones formales de la teneduría de los libros contables utilizados en el ámbito del comercio han sido consideradas como un modelo de toma de notas y registro general de la información que influyó notablemente en el trabajo intelectual desde la modernidad temprana ${ }^{38}$. Más aun, como ha destacado Mary Poovey, el registro de los movimientos comerciales cotidianos y su organización en estos libros con cuadros de doble entrada [double-entry bookkeeping] fue uno de los primeros sistemas que privilegiaron tanto a las cosas en sí mismas (los objetos y el dinero que los mercaderes transaban) como al sistema formal de su inscripción en forma de número, transformando así a

\footnotetext{
37 Ross Johnson, 1868. Hünicken, 1894. Furlong, 1964.

38 Blair, 31 (Chicago, 2004): 85-107; Blair, 2010.
} 
las representaciones de aquellas «cosas» en datos usables ${ }^{39}$. De ese modo, en tanto sistema de escritura, estos cuadros de doble entrada tuvieron un efecto amplio, de carácter epistemológico, que habría excedido el estrecho ámbito de las operaciones de transcripción y cálculo económico, consolidando así una imagen de rigurosidad formal y precisión que se habría extendido finalmente hacia todos los dominios del conocimiento.

Lafone Quevedo atribuía precisamente a esta suerte de «arte de de la tabulación» las conclusiones y descubrimientos más importantes que había realizado referidos a los distintos mecanismos de aglutinación de las partículas pronominales en las lenguas del Chaco:

[But] let us take the case of an agglutinating tongue. A priori we know it to be made up of various roots and particles with a more or less definite meaning. Let us then hunt them through all stocks and branches and «see what we get from tabulating the results of such investigations. What I have been able to learn as regards Mocoví, Abipón, etc. is mainly the outcome of tabulation» ${ }^{40}$.

Según se puede deducir de su colección de manuscritos con transcripciones de vocabularios, el método de trabajo utilizado para la organización y posterior comparación de los datos consistía en transcribir los listados de vocablos en una serie de cuadernillos de 18 por 24 centímetros, que se obtenían de recortar en forma transversal, por el medio o en tres partes, unos pliegos de papel rayado. Si bien cada cuadernillo contaba con unas 12 o 16 carillas utilizables, para evitar las confusiones generadas por la mezcla de pliegos, Lafone Quevedo y su asistente escribían sobre las carillas impares, organizando alfabéticamente las entradas y asentando en una columna los vocablos en idioma indígena, y en una columna contigua, sus equivalentes en castellano. Cada cuadernillo llevaba inscripto en su margen superior una sigla, a veces abreviada, que refería el idioma del que se trataba, junto con un número que refería el orden sucesivo dentro del conjunto. Una vez finalizado el vocabulario se reunían todos los cuadernillos y se los almacenaba entre dos tapas de cartón blando o duro, que en algunos casos contaban con cintas insertas para ajustarlas y formar así un paquete cerrado, o eran atadas directamente con hilo sisal. Organizados de este modo, los vocabularios y los manuscritos en general no sólo eran fáciles de manejar, transportar y almacenar, sino que facilitaban tanto el trabajo de transcripción como el de comparación posterior entre las distintas lenguas. En el primer caso, al estar

\footnotetext{
39 Poovey, 1998: 29-91.

40 [Lafone Quevedo, manuscrito sin título], colección de manuscritos de Lafone Quevedo, n. ${ }^{\circ}$ 34, Archivo Histórico del Museo de La Plata (AHMLP). El entrecomillado del texto es del autor.
} 
sueltos, los cuadernillos eran fácilmente reemplazables si se cometían errores de transcripción o si aparecían nuevos vocablos, que podían agregarse rápidamente desechando solamente el cuadernillo correspondiente sin alterar el conjunto ${ }^{41}$. En el segundo caso, podían extraerse de cada paquete referido a cada lengua los cuadernillos, por ejemplo, correspondientes a la letra «A»y cotejar las diferencias y similitudes entre vocablos colocando los cuadernillos uno al lado del otro $^{42}$.

Para perfeccionar este sistema de comparación Lafone Quevedo realizó para cada lengua versiones de los mismos cuadernillos siguiendo el orden alfabético, pero invirtiendo el orden expositivo, consignando en primer lugar la columna correspondiente a los vocablos indígenas y en la segunda sus equivalentes en castellano, para facilitar así la comparación entre raíces. $\mathrm{Al}$ referirse a su trabajo de edición crítica de un manuscrito de Alcide d'Orbigny (1802-1857) relativo a la lengua Vejoz que Lucien Adam le envió, comentó:

El vocabulario, que está en la forma de Castellano-Vejoz se ha reducido al orden estrictamente alfabético, sin distinción de palabras como en el original, y para el cotejo de las raíces se ha invertido al Vejoz-Castellano también. Esto es indispensable para todo estudio acertado de una lengua. Este procedimiento «tan puramente mecánico suele aclarar más de cuatro misterios, facilita el descubrimiento de las raíces, la forma de las partículas temáticas y nos da pistas importantes para determinar la fonología y la morbosidad de ciertos sonidos en cada lengua» ${ }^{43}$.

Por otro lado, dada la importancia preponderante que Lafone Quevedo le asignaba, por su valor clasificatorio, a las partículas pronominales y a sus formas de articulación en el establecimiento de los «mecanismos gramaticales», las colocaba en la primera hoja del primer cuadernillo, antes de las listas léxicas ordenadas alfabéticamente ${ }^{44}$. Una vez finalizados y corregidos los cuadernillos con los vocabularios, la información era transcripta en una serie de libros encuadernados compuestos de hojas cuadriculadas donde adquiría un formato fijo y definitivo, listo para la publicación.

${ }^{41}$ Carta del asistente Ramón Martínez a Samuel A. Lafone Quevedo, Pilciao, 2 de marzo de 1894, AHMLP, colección de manuscritos, legajo n. ${ }^{\circ} 138$.

${ }^{42}$ Incluso estos cuadernillos tienen marcas que indican que fueron doblados por la línea media, lo que sugiere que al colocarlos así doblados al lado de las columnas correlativas de otros cuadernillos permitirían de manera ágil la comparación entre cuadernillos referidos tanto a lenguas distintas, como a una misma lengua.

${ }^{43}$ Lafone Quevedo, XVII (Buenos Aires, 1896a): 134-135. El entrecomillado del texto es del autor.

${ }^{44}$ Lafone Quevedo, XVII (Buenos Aires, 1896c): 332. 
Para aumentar estas colecciones el plan de trabajo de la sección del Museo a su cargo incluyó también la obtención de nuevos datos lingüísticos con fines comparativos, apelando a la cooperación de recolectores residentes en zonas de contacto con los grupos indígenas. Para ello Lafone Quevedo redactó en 1892 unas «Instrucciones del Museo de La Plata para los colectores de vocabularios indígenas» donde se detallaban de manera resumida aquellos aspectos de importancia que los posibles colaboradores debían relevar ${ }^{45}$. Es de destacar aquí que, como ha señalado Claude Blanckaert, en el repertorio de las instrucciones desplegado por las sociedades eruditas a lo largo del siglo XIX, fueron muy especialmente aquellas referidas a la lingüística las que más debieron combatir la arbitrariedad y la confusión resultante de las observaciones recogidas sin orden ni método por un abigarrado conjunto de colaboradores en el campo ${ }^{46}$. En primer lugar, los trabajos de relevamiento lingüístico exigían de una cierta preparación y de conocimientos técnicos generales referidos sobre todo a las estructuras gramaticales que no era habitual encontrar en los viajeros. Esto redundaba en la confección de léxicos incompletos, formados por palabras aisladas desprovistas de todo contexto y recogidas al acaso, que resultaban de poca utilidad para la posterior sistematización y comparación en el gabinete, en especial al momento de establecer los elementos formales gramaticales, las afinidades morfológicas y las características propias de una determinada lengua ${ }^{47}$. En segundo lugar, se debía lograr que el viajero soslayara el «azar del oído» reduciendo, por un lado, la diversidad de formas ortográficas al momento de registrar los datos $\mathrm{y}$, por otro, evitando a la hora de hacer preguntas a los informantes la influencia de ideas abstractas acerca de los aspectos formales de la lengua:

Les gens qu'on interroge sont d'habitude incapables de comprendre les formes grammaticales, les pronoms isolés, etc. Ils parlent leur langue naturellement, mais ils ne l'ont jamais raisonnée. Les mots non déclinés ou conjugués n'ont jamais une acception assez précise pour être reconnus par le populaire illettré. Il ne faut leur donner à traduire que des phrases courtes et claires, composées d'un petit nombre de mots choisis avec soin et combinés de façon à se représenter sous differentes formes grammaticales; c'est seulement ainsi qu'on établira avec certitude les cas, les terminaisons, les désinences, etc. ${ }^{48}$.

\footnotetext{
${ }^{45}$ Acerca del uso de las instrucciones a fínes del siglo XIX, véase Podgorny, 2002.

46 Blanckaert, 2009: 38-40.

47 Vinson, III (París, 1880): 193-196.

48 Ibidem: 194-195.
} 


\section{En el mismo sentido se expresaba con elocuencia Lafone Quevedo:}

Quien no haya hecho la prueba dirá que esto de hacer vocabularios es tan fácil como recoger margaritas en un campo florido; pero la verdad es que aparte de la esquivez de todo Indio, tenemos que luchar con dos dificultades magnas; la primera hacer comprender al Indio lo que queremos decir; la segunda, apuntar bien lo que oímos. El Indio que piensa en frases nada sabe de palabras sueltas ni, mucho menos, de letras; y después emplean sonidos que es imposible reproducir con nuestro alfabeto, dado el caso de haberlos oído bien [...] [así] todo vocabulario reunido por quien quiera que sea, debe ser sometido a las más duras pruebas léxicas y fonológicas ${ }^{49}$.

Para salvar este tipo de inconvenientes, en el último tercio del siglo XIX se introdujo un cambio sustancial que reemplazaba la colecta indiscriminada de vocablos sueltos por una serie de cuestionarios organizados a partir de frases que revelaban antes bien aquellos aspectos gramaticales de interés para el estudio comparativo. Este nuevo formato que adquirieron las instrucciones, compuesto por una lista detallada de cuestiones breves y concisas de carácter prescriptivo, tenía como objeto coordinar y restringir al máximo la «ecuación personal de los recolectores en el campo ${ }^{50}$. Es en esta línea donde se inscriben las instrucciones que Lafone Quevedo redactó para la sección a su cargo en el Museo de La Plata. Se destaca, en primer lugar, que las mismas están estructuradas partiendo de la gramática del lenguaje ${ }^{51} \mathrm{y}$ en consecuencia exigían un mínimo de pericia en ese tema, en especial en los apartados dedicados a los verbos y las variantes de sus conjugaciones. En ese sentido los misioneros de las distintas ordenes religiosas diseminados por el interior del país, con quienes Lafone Quevedo estaba empezando a tomar contacto epistolar, se contaban entre los colectores que en ocasiones poseían una preparación cuanto menos rudimentaria para la tarea y a veces también con un conocimiento previo de primera mano de las lenguas indígenas. En segundo lugar, en la parte referida a los datos del alfabeto que los colectores debían utilizar para la transcripción, se solicitaba la equivalencia de sonidos no sólo con la ortografía del castellano, sino también con las del inglés, el portugués

49 Ángel Justiniano Carranza, Vocabulario Toba [manuscrito], AHMLP, colección de manuscritos, legajo n. ${ }^{\circ} 20$.

${ }^{50}$ Blanckaert, 2009. En la práctica astronómica, el concepto de «ecuación personal» remitía al trabajo cooperativo de estandarización de los errores en la toma de las coordenadas de las estrellas, cuyo control era indispensable para poder compartir los datos obtenidos en diferentes espacios y por distintos observadores. Rieznik, 2010.

${ }^{51}$ Las instrucciones están divididas en las siguientes secciones: «Alfabeto», «Nombres Sustantivos», «Nombres Adjetivos», «Pronombres», «Verbos»y «Adverbios». Lafone Quevedo, III (La Plata, 1892b): 401-416. 
y el italiano, lo que indicaría que se pensaba en abarcar la mayor cantidad posible de colaboradores previendo las distintas nacionalidades de los mismos. En tercer lugar, se solicitaba un listado detallado de aquellos sustantivos utilizados para referirse a los actos de orinar, defecar y copular y también de los referidos a las «naturas de cada sexo», debiendo apuntarse «tanto los groseros como los pulidos, porque muchas veces estos nada tienen que ver con el verdadero apelativo de la cosa» ${ }^{52}$. Este registro de los usos «bajos» de la lengua y de aquellos actos que eran pasibles de punición divina, sugiere también que Lafone Quevedo apelaba a la colaboración de un grupo amplio de recolectores que no se restringía solamente a los misioneros quienes, por preceptos morales, evitaban ocuparse de aquellos ${ }^{53}$. Por último, se solicitaba la traducción «lo más literal que se pueda» del Padre nuestro, recomendando poner especial cuidado en los casos en que hubiera que cambiar las frases debido a que «el indio no siempre puede reproducir nuestro romance». La importancia preponderante que Lafone Quevedo le otorgaba a las variantes indígenas del Pater noster radicaba, por un lado, en que para el trabajo de comparación existía un importante registro de las mismas en las obras del jesuita Lorenzo Hervás y Panduro (1735-1809) Catalogo delle lingue conosciute (1784), cuya versión castellana había sido publicada en Madrid, en seis volúmenes, entre 1800 y 1805 bajo el título Catálogo de las lenguas, ${ }^{54}$, así como en la obra de Johann Christophe Adelung Mithridathes oder allgemeine Sprachenkunde mit dem Vater Unser als Sprachprobe in bey nahe fünfhundert Sprachen und Mundarten (1806-1817). Pero también tenía gran importancia el hecho de que en esa oración se hacía un uso intensivo de la articulación de los pronombres y las partículas pronominales.

\section{La Biblioteca lingüística del Museo de la Plata}

Utilizando como base la información referida a las lenguas del Chaco que Lafone Quevedo había logrado recopilar y organizar entre 1890 y 1893 con los manuscritos aportados por Mitre, Lamas, Carranza y los misioneros, Moreno le ofreció la creación de una Biblioteca Lingüística del Museo de La Plata, entendida como un sucedáneo local de la afamada Bibliothèque linguistique

52 Ibidem: 405.

53 Véase al respecto Vinson, III (París,1880): 194. Lafone Quevedo, XVII (Buenos Aires, 1896b): 619-620.

${ }^{54}$ Uno de los volúmenes, titulado Saggio prattico delle lingua, contenía versiones del Padre Nuestro en mas de 300 lenguas. 
américaine que apareció en Francia en la década de 1870, dirigida por Lucien Adam. El plan editorial pergeñado junto con Moreno abarcaría:

[...] todas las lenguas que se hablan ó se han hablado en el perímetro de lo que fue el virreynato del Río de la Plata, lo que equivale a decir que se incluirá en ella más de la mitad de todos los grupos de idiomas de la América del Sud. Para conseguir este objeto, se publicarán todos los MSS inéditos que se puedan conseguir, los libros raros que no están al alcance del público y las noticias que sucesivamente vayan adquiriéndose según las instrucciones que para este caso ha distribuido el Museo en esta República y las vecinas. Así podrán los estudiantes de nuestras lenguas adquirir a poco costo ediciones de MSS y obras raras, que son las joyas de bibliotecas públicas y particulares, y rara vez están al alcance del interesado, y también de mucho que estaba a pique de perderse para el Americanista del porvenir, por la rápida desaparición de tribus y grupos enteros de naciones ${ }^{55}$.

El proyecto establecía que las ediciones críticas de los manuscritos aparecerían en la Revista del Museo y posteriormente serían reunidos y editados aparte, en ediciones reducidas de 230 ejemplares que serían traducidas al inglés y al francés. El primer tomo se referiría a la lengua Mocoví en base a los manuscritos del Padre Tavolini aportados por Mitre. Los tomos segundo y tercero estarían dedicados respectivamente al Toba, a partir de un manuscrito del Padre Bárzena, y al Mataco y sus codialectos, incluyendo los datos que habían sido recolectados por los misioneros de la Orden Seráfica siguiendo las instrucciones de $1892^{56}$. Sin embargo, la concreción de este plan editorial quedó en el ámbito de las promesas, viéndose pronto frustrado por la nueva orientación que Moreno le imprimió al Museo de La Plata, más ligada a las exploraciones para la determinación de los límites internacionales del país. Esto afectó muy especialmente al desarrollo de los trabajos en todas aquellas secciones que no estaban relacionadas de manera directa con ese nuevo objetivo, como lo eran las secciones referidas a la antropología y la arqueología, a las que se agregaba ahora la sección de lingüística ${ }^{57}$. Más aún, no llegaron a consolidarse dos proyectos propuestos por el estudioso Juan Bautista Ambrosetti (1865-1917) y por el explorador italiano Guido Boggiani (1862-1902) para formar una sección etnográfica, que contemplaban el ordenamiento y catalogación de las colecciones del Museo, la realización de viajes de exploración y la publicación de los resultados en series especializadas profusamente ilustradas ${ }^{58}$. Regresando al caso de Lafone Quevedo, de la proyectada

55 Moreno, 1893: iii.

56 Ibidem: iv-v.

57 Farro, 2009.

58 Ambrosetti fue un estudioso dedicado a la arqueología, la etnografía y el folklore del noroeste argentino. Fue director de la Sección Zoológica del Museo de Entre Ríos (1886), 
Biblioteca Lingüística, apareció en 1893 solamente el primer tomo dedicado a la lengua Mocoví. Su manuscrito de la edición crítica de la lengua Toba, que originalmente debía aparecer ese mismo año como el segundo tomo de la mencionada serie, fue retenido por Moreno, quién decidió publicarlo en dos partes separadas que aparecieron en 1896 y en 1899, pero solo como trabajos corrientes en la Revista del Museo.

\section{HACIA UNA «GEOGRAFÍA HISTÓRICA» DE LAS LENGUAS ARGENTINAS}

Los retrasos editoriales establecidos por Moreno y el incumplimiento de sus promesas complicaron los planes de trabajo de Lafone Quevedo, que en ese entonces se hallaba en fluida relación epistolar para el intercambio de publicaciones y vocabularios con estudiosos como Adam y con los numerosos corresponsales que habían comenzado a enviarle datos en respuesta a sus «Instrucciones» de $1892^{59}$. Por ese motivo, empezará a publicar la mayor parte de sus trabajos en los Anales de la Sociedad Científica Argentina, en el Boletín de la Academia Nacional de Ciencias de Córdoba y, sobre todo, en el Boletín del Instituto Geográfico Argentino ${ }^{60}$. Esta última asociación, creada en 1879, se transformará en el transcurso de la década de 1890 en uno de los espacios principales para el desarrollo de estudios referidos a la lingüística,

naturalista viajero del Museo de La Plata (1892), director del Museo Arqueológico y Etnográfico del Instituto Geográfico Argentino (1896) y encargado de la Sección Arqueología del Museo Nacional de Buenos Aires (1903). En 1904 fundó el Museo Etnográfico, dependiente de la Facultad de Filosofía y Letras de la Universidad de Buenos Aires, organizando desde alli las expediciones arqueológicas a las localidades de Pampa Grande y La Paya en la región Noroeste. Al respecto véase Pegoraro, 2009.

59 Lafone Quevedo, XVII (Buenos Aires, 1896a): 121-176. Lafone Quevedo le comentó por carta al general Mitre el nuevo proyecto editorial que había ideado con Ambrosetti para publicar una serie de monografías que tenía listas sobre las distintas variantes dialectales de las lenguas del Chaco y que no habían quedado retenidas en la imprenta del Museo de La Plata: "Vamos adelante con la serie. Ambrosetti ya tiene en sus manos dos de las cuatro monografías indicadas, y también otra sobre los Guaycurúes Mbayas. Mi Abipón ya está concluido y busco quien me lo publique. La Revista del Museo de La Plata "está tan llena de material que no tiene lugar ni para el famoso manuscrito de Bárcena"». Carta de Lafone Quevedo al general Mitre, Pilciao, 11 de abril de 1896, Museo Mitre, 1912: 380-381, el entrecomillado es del autor.

${ }^{60}$ «Tengo el gusto de anunciarle que la Academia en Córdoba, publicará en seguida mi De Abiponius, y la Sociedad Científica en esa el Guaycurú. "Veremos si esto le sirve de estímulo a Moreno para que concluya el Toba"». Carta de Lafone Quevedo al general Mitre, Pilciao, 25 de mayo de 1896, Museo Mitre, 1912: 382-383, el entrecomillado nos pertenece. 
la etnografía y la arqueología ${ }^{61}$. Lafone Quevedo encontrará allí el ámbito para continuar con sus trabajos de síntesis referidos a la clasificación de las lenguas del Chaco y, sobre todo, para llevar a cabo un temprano y ansiado proyecto de elaboración de mapas étnico-lingüísticos. El objeto del mismo era el de establecer una "geografía histórica» de las lenguas indígenas del territorio argentino pertenecientes al «grupo del medio», a la que consideraba «importantísima para la clasificación acertada de estas» ya que, argumentaba, «muchos puntos oscuros de etnología y filología se esclarecen con la simple ubicación de las tribus en su propio lugar; porque así se ve como las homofonías entre dos lenguas pueden deberse a contacto geográfico» ${ }^{62}$. Ese proyecto tomaba como base, por un lado, la información contenida en las Relaciones Geográficas de fines del siglo XVI — que habían comenzado a ser publicadas en España al cuidado de Marcos Jiménez de la Espada (1831-1898) - y, por otro, todos aquellos datos de carácter histórico y etnográfico extraídos de las obras de los cronistas, de los documentos compulsados en los archivos regionales y en los acervos de estudiosos como Mitre, Lamas y Trelles. Así, para establecer los cambios en las ubicaciones geográficas de los distintos grupos lingüísticos consignaba en los mapas los nombres de lugar que tenía tabulados para el estudio de los cambios en la toponimia, haciendo colocar una fecha debajo del nombre de un lugar para señalar que un grupo dado se «hallaba allí en el siglo indicado, pero que en la actualidad no permanece ya en aquel sitio» ${ }^{63}$.

Ese conjunto de datos étnicos e históricos sistematizado por Lafone fue preparado tomando también en cuenta las cartas que los miembros del Instituto estaban levantando en un contexto de conflictividad creciente generado por el establecimiento de los límites entre las provincias con motivo de la división de los «territorios nacionales». Ejemplo de esto es el mapa que marcaba los límites entre la provincia de Santiago del Estero y los territorios del Chaco que había sido sistematizado por el ingeniero Alejandro Gancedo en $1896^{64}$. En el diseño de estos mapas Lafone Quevedo integrará también todos aquellos datos contemporáneos que le habían comenzado a enviar sus corresponsales. En efecto, con el apoyo editorial del Instituto asegurado y gracias a los contactos aportados por el general Mitre y por Ambrosetti, pudo urdir con eficacia una red de colaboradores en el campo. Estos le enviaban datos sobre las lenguas indígenas y sobre todo información acerca de la ubicación y dispersión geo-

\footnotetext{
${ }^{61}$ Podgorny y Lopes, 2008. Pegoraro, 2009.

${ }^{62}$ Lafone Quevedo, XVII (Buenos Aires, 1896a): 128.

${ }^{63}$ Lafone Quevedo, XVII (Buenos Aires, 1896b): 621.

${ }^{64}$ Ibidem: 176.
} 
gráfica que en ese momento tenían los distintos grupos hablantes, para poder cotejarlos con los datos que se habían registrado desde el siglo XVI ${ }^{65}$. Para Lafone, la compilación y organización en los mapas de los datos antiguos y modernos referidos a las sucesivas ubicaciones de los grupos indígenas permitían apreciar visualmente tanto los sucesivos cambios de ubicación de los grupos indígenas a lo largo del tiempo, como inferir los posibles contactos facilitados por la proximidad que servirían para explicar las similitudes gramaticales y léxicas entre las lenguas. Es importante destacar aquí que años más tarde, cuando Lafone Quevedo era ya director del Museo de La Plata, sostendrá con énfasis este criterio de respetar las divisiones geográficas históricas de los territorios a la hora de elaborar también las clasificaciones arqueológicas, ya que entendía que una clasificación basada con exclusividad en los límites políticos contemporáneos falseaba la visión histórica sobre las sociedades que no vivieron de acuerdo a esas fronteras ${ }^{66}$.

Entre sus principales colaboradores en el campo se destacaron los misioneros de distintas ordenes religiosas, como los padres Doroteo Gianecchini, Ignacio Massei y Eliseo Molina (Colegio Franciscano de Tarija, Bolivia), Fray Mateo Venanzetti y Zacarías Ducci (San Lorenzo, Corrientes); Fray Leandro Bianchi y Joaquín Remedi (Convento de San Francisco, Salta), el Presbítero Ojeda (Villa Concepción, Tucumán) y Bernabé Piedra Buena (Seminario Conciliar de Salta), entre otros. Asimismo, el comerciante y explorador italiano Guido Boggiani, residente en el Paraguay fue uno de los principales colaboradores con el que Lafone Quevedo estrechó vínculos de mutua cooperación para poder establecer las similitudes y diferencias entre algunas de las lenguas de la región del Chaco y la ubicación geográfica de su hablantes contemporáneos. Con todos ellos articuló un esquema de trabajo para el intercambio de datos que remite a la forma de «etnografía epistolar» definida por Stocking para el siglo XIX, donde los estudiosos dependían de la información de primera mano que podían recolectar especialmente aquellos colaboradores que residían próximos a los grupos indígenas ${ }^{67}$. Este esquema de trabajo se apoyó en lo que Kuklick dio en llamar la «estructura social del método comparativo» que implicaba, entre otras cosas, una forma de recolección de datos por medio de instrucciones y la separación entre recolectores y compiladores, organización

${ }^{65}$ Esa información fue incorporada a los mapas por los ingenieros del Instituto que trabajaban en el trazado de las líneas de ferrocarril en el interior del país, como los italianos Giovanni Pelleschi (1846-1922) y su yerno Guido Jacobacci (1864-1922). Lafone Quevedo, XVII (Buenos Aires, 1896b): 121-176.

${ }_{66}$ Al respecto véase discusión en Podgorny, VI / 1 (Rio de Janeiro, 1999): 81-100.

${ }^{67}$ Stocking, 1995: 16. 
del trabajo que la antropología habría tomado de la historia natural ${ }^{68}$. Así, por medio de la correspondencia Lafone Quevedo dirigió las actividades de Boggiani en el campo dándole no solo instrucciones acerca de qué elementos relevar - enfatizando en la obtención de las partículas pronominales-, sino también enviándole vocabularios, copias de mapas, transcripciones de capítulos enteros de las obras de los cronistas realizadas por su asistente y todos aquellos datos que fueran de utilidad a la hora de relevar información ${ }^{69}$. Con este bagaje, Boggiani se internaba en las selvas paraguayas siguiendo a las incursiones estacionales que realizaban los indígenas para cazar ciervos, cuyos cueros les compraba para vender en Europa ${ }^{70}$. En esas travesías compilaba vocabularios, sacaba fotografías, copiaba dibujos de los tatuajes corporales y averiguaba datos referidos a las relaciones entre los grupos y sus cambios de residencia a lo largo del tiempo ${ }^{71}$. También aprovechaba para esto las oportunidades que brindaba la presencia ocasional de los indígenas en Puerto Casado o en Asunción, cuando bajaban a comerciar sus productos. A su turno, Lafone Quevedo incorporaba en Pilciao los datos que le enviaba Boggiani, cotejando y corrigiendo la información con aquella que le remitían los misioneros, con las fuentes publicadas y con los documentos de archivo. También gestionaba apoyos para el trabajo del explorador italiano, en forma de espacios de publicación en el Boletín del Instituto Geográfico Argentino, el envío de pequeñas sumas de dinero para sus expediciones y por medio de la edición y corrección de los manuscritos que aquel le remitía para enviar a publicar. En estrecha colaboración, desde las páginas del Boletín ambos se dedicaron a enmendar lo que consideraban como errores de concepto y de clasificación en los trabajos que Brinton había publicado desde comienzos de la década del 1890, en especial en lo referido a su esquema de clasificación de las lenguas del Chaco y sobre todo a la ubicación geográfica de los grupos que aquel diera en su trabajo "The Linguistic Cartography of the Chaco Region"72. Boggiani, que tenía formación artística y manejaba los rudimentos del dibujo topográfico, elaborará un mapa con el asesoramiento de Lafone Quevedo para ilustrar aquellos puntos en los que ambos diferían con Brinton.

${ }^{68}$ Kucklick, 1997: 47-65; XVI / 1 (Canberra, 2007): 51-66.

${ }^{69}$ Carta de Guido Boggiani a Samuel A. Lafone Quevedo, 11 de junio de 1897, AHMLP, colección de manuscritos, legajo n. ${ }^{\circ} 144$.

${ }^{70}$ Carta de Guido Boggiani a Samuel A. Lafone Quevedo, 5 de julio de 1897, AHMLP, colección de manuscritos, legajo n. ${ }^{\circ} 144$.

${ }^{71}$ Boggiani, 1894; 1895; XVIII (Buenos Aires, 1897): 613-625.

72 Brinton, 1891; XXXVII (Philadelphia, 1898): 178-203. Lafone Quevedo, XIV (Buenos Aires, 1893): 505-528; XX (Buenos Aires, 1899): 1-64. Boggiani, XVIII (Buenos Aires, 1897): 613-625. 
Por último, nos interesa señalar que esta forma de trabajo de Lafone Quevedo que integraba, por un lado, la información obtenida en los archivos, en las fuentes publicadas, en los vocabularios recogidos por él in situ y en los datos contemporáneos enviados por corresponsales, marcaba una diferencia con las prácticas llevadas a cabo simultáneamente por estudiosos como Brinton. En efecto, como ha señalado Curtis Hinsley, este último puede ser considerado como un «New World classicist» cuyas prácticas se relacionaban antes bien con las del bibliófilo interesado en recuperar un registro textual de la historia del hemisferio entendido como un todo, resaltando así el carácter de unicidad, originalidad y «destino manifiesto» del continente ${ }^{73}$. Esta concepción implicó una forma de proceder que en ocasiones tendía a pasar por alto los límites entre las naciones americanas y a borrar las particularidades étnicas. Algunas de estas características, como el uso de una escala continental y las prácticas de la compulsa de manuscritos y de la adquisición de «obras raras» en las bibliotecas y librerías anticuarias con la pericia propia del bibliófilo, también pueden encontrarse en los trabajos que desarrolló el general Mitre para el estudio de las lenguas americanas ${ }^{74}$. En ese sentido, el caso de Lafone Quevedo, cuyos estudios se ceñían a una región muy concreta de la América meridional e incorporaban datos contemporáneos relevados por él y por los corresponsales en el campo, muestra una orientación incipiente hacia las formas de trabajo que comenzaban a imponerse hacia fines del siglo XIX y con más fuerza a comienzos del siglo XX, que se caracterizarían por la circunscripción regional y la paulatina identidad entre el recolector y el sistematizador de los datos lingüísticos ${ }^{75}$.

\section{OBSERVACIONES FINALES}

En este artículo hemos analizado el contexto de producción de los trabajos relacionados con las clasificaciones lingüísticas que Samuel Alexander Lafone Quevedo desarrolló desde comienzos de la década de 1880, señalando que las prácticas relacionadas con sus emprendimientos comerciales habrían influido de dos maneras sobre el desarrollo de aquellos. Por un lado, la búsqueda de información de carácter jurídico-administrativa en los documentos de los archivos de la provincia y de particulares referida a los títulos de propiedad

\footnotetext{
73 Hinsley, 91 (Washington DC, 1989): 775-776.

74 Torres, 1909. Imbelloni, 1939. Buchbinder, 13 (Buenos Aires, 1996): 59-82. Crespo, 2008. Acerca de los trabajos históricos de Mitre, véase Devoto y Pagano, 2009.

${ }^{75}$ Las obras de los alemanes Karl von den Steinen (1855-1929), Paul Ehrenreich (18551914) y Theodor Koch-Grünberg (1872-1924) constituyen un ejemplo de esto último.
} 
de la tierra para la expansión de su empresa le posibilitó el hallazgo de datos referidos a la toponimia local y a los apellidos de los grupos indígenas que habitaron la región desde el siglo XVI. Con esa información escribió sus primeros trabajos referidos a la historia del antiguo Tucumán y a la toponimia regional, estudiando la lengua Cacana y componiendo al efecto un Thesaurus o «Vocabulario Catamarcano». Por otro lado, las convenciones formales del registro de la información de carácter comercial influyeron en sus trabajos de ordenamiento de los datos para el estudio comparativo entre las lenguas del Chaco, componiendo una suerte de «arte de la tabulación» que empleó en lo sucesivo en sus trabajos de clasificación que realizó para el Museo de La Plata y el Instituto Geográfico Argentino. En relación a esto último, señalamos que la nueva orientación que Moreno le imprimió hacia 1893 al Museo de La Plata y la periodicidad que le diera a sus publicaciones, suspendiendo la edición de la proyectada Biblioteca Lingüística, alteró los planes de trabajo que Lafone Quevedo tenía para la sección a su cargo en esa institución, precisamente en el momento en que comenzaba a recepcionar la información que había solicitado a los corresponsales por medio de las instrucciones lingüísticas que había diseñado al efecto. Por ese motivo, comenzó a enviar sus trabajos de síntesis y clasificación al Instituto Geográfico Argentino donde, con el apoyo de Ambrosetti aparecerán regularmente en su Boletín. En unos pocos años Lafone pudo consolidar gracias a ese apoyo editorial su proyecto de una «etnografía lingüística» para el establecimiento de una "geografía histórica» de las lenguas indígenas del territorio argentino - en especial de aquellas circunscriptas a la región del Chaco - y cuyo límite cronológico será el período que abarca desde mediados del siglo XVI hasta fines del siglo XIX inclusive. Asimismo destacamos que desde su fundo en Pilciao, Lafone Quevedo erigió una suerte de nodo en una red por donde circulaban datos lingüísticos en forma de manuscritos, cartas y publicaciones, red que articulaba los espacios de su estudio y biblioteca en Catamarca con los emplazamientos institucionales en Buenos Aires y La Plata, los colaboradores en el campo y los estudiosos de las lenguas indígenas americanas residentes en el extranjero. La integración de datos contemporáneos provistos por los corresponsales, con la información relevada en los documentos de archivo y en los libros publicados referidos a las lenguas de la América meridional, marcaban una diferencia con respecto a las prácticas llevadas a cabo por estudiosos como Brinton y Mitre, quienes hicieron de la exégesis de manuscritos y libros su método de trabajo principal. Por su parte, el corpus de datos organizado por Lafone Quevedo también tuvo su correlato visual en una serie de mapas étnico-lingüísticos a partir de los cuales discutirá con Brinton hacia fines de la década de 1890 problemas relativos a la clasificación de las lenguas del Chaco. 


\section{BIBLIOGRAFÍA}

Aufiero, Diego, “El Instituto Bonaerense de Numismática y Antigüedades y los estudios numismáticos en Buenos Aires en la década de 1870", L'Ordinaire Latinoaméricain, 212 (Toulouse, 2010): 159-182.

Auroux, Sylvain et Queixalós, Francisco, Pour une histoire de la linguistique amérindenne en France, París, AEA-CNRS, 1984.

Auroux, Sylvain, "Introduction. Émergence et domination de la grammaire comparée", Sylvain Auroux (dir.), Histoire des idées linguistiques. L'hégémonie du comparatisme, tomo III, Belgique, Pierre Mardaga éditeur, 2000: 9-22.

Bixio, Beatriz, "Lenguas indígenas del Centro y Norte de la República Argentina (Siglos XVI-XVIII)", Eduardo E. Berberian y Axel E. Nielsen (dirs.) Historia Argentina Prehispánica, tomo II, Córdoba, Editorial Brujas, 2001: 875-936.

Blair, Anne, "Note Taking as an Art of Transmission", Critical Inquiry, 31 (Chicago, 2004): 85-107.

Blair, Anne, Too Much to Know. Managing Scholarly Information before the Modern Age, New Haven, Conn., Yale University Press, 2010.

Blanckaert, Claude, "Le fait et la valeur: disciplines de l'observation dans les instructions ethnographiques (XVIII ${ }^{\mathrm{e}}-\mathrm{XIX}^{\mathrm{e}}$ siècle)", Sylviane Albertan-Coppola (ed.), Apprendre à porter sa vue au loin: Hommage à Michèle Duchet, Lyon, ENS Editions, 2009: 29-56.

Boggiani, Guido, I Chiamacoco, Roma, Società Romana per L'Antropologia, 1894.

Boggiani, Guido, Viaggi d'un artista nell' America Meridionale. I Caduvei (Mbayá o Guaycurú), Roma, Ermanno Loescher \& Co., 1895.

Boggiani, Guido, "Etnografía del Alto Paraguay", Boletín del Instituto Geográfico Argentino, XVIII (Buenos Aires, 1897): 613-625.

Brinton, Daniel G., The American Race. A Linguistic Classification and Ethnographic Description of the Native Tribes of North and South America, New York, N.D.C. Hodges, 1891.

Brinton, Daniel G., "The Linguistic Cartography of the Chaco Region", Proceedings of the American Philosophical Society, XXXVII (Philadelphia, 1898): 178-203.

Buchbinder, Pablo, "Vínculos privados, instituciones públicas y reglas profesionales en los orígenes de la historiografía argentina", Boletín del Instituto de Historia Argentina y Americana "Dr. Emilio Ravignani”, 13 (Buenos Aires, 1996): 59-82.

Canclini, Arnoldo, "Samuel F. Lafone: apuntes para su biografía”, Investigaciones y Ensayos, 48 (Buenos Aires, 1999): 123-161. 
Crespo, Horacio, "El erudito coleccionista y los orígenes del americanismo", Carlos Altamirano (ed.), Historia de los intelectuales en América Latina, vol. 1, Buenos Aires, Katz Editores, 2008: 290-311.

Desmet, Piet, La linguistique naturaliste en France (1867-1922), Leuven, Peeters Publishers, 1996.

Devoto, Fernando y Pagano, Nora, Historia de la historiografía argentina, Buenos Aires, Sudamericana, 2009.

Dias, Nélia, Rupp-Eisenreich, Britta, "Linguistique et anthropologie physique", Sylvain Auroux (dir.), Histoire des idées linguistiques. L'hégémonie du comparatisme, tomo III, Belgique, Pierre Mardaga éditeur, 2000: 279-294.

Farro, Máximo, La formación del Museo de La Plata. Coleccionistas, comerciantes, estudiosos y naturalistas viajeros a fines del siglo XIX, Rosario, Prohistoria ediciones, 2009.

Furlong, Guillermo, Samuel A. Lafone Quevedo, Buenos Aires, Ediciones Culturales Argentinas, 1964.

Groussac, Paul, Memoria Histórica y Descriptiva de la provincia de Tucumán, Buenos Aires, Imprenta de Martín Biedma, 1882.

Hinsley, Curtis, "Book review: Regna Darell Daniel Garrison Brinton: The 'Fearless Critic' of Philadelphia”, American Anthropologist, 91 (Washington DC, 1989): 775-776.

Hünicken, Émil, Industria Minera y Metalúrgica en las provincias de La Rioja, Catamarca, Jujuy y Salta, Buenos Aires, Imprenta de Juan A. Alsina, 1894.

Imbelloni, José, "Introducción: Lenguas indígenas del territorio argentino", Ricardo Levene (dir.), Historia de la Nación Argentina. Desde los orígenes hasta la organización definitiva en 1862, vol. 1, Buenos Aires, Academia Nacional de la Historia-El Ateneo, 1939: 203-223.

Kuklick, Henrika, "After Ishmael: The fieldwork tradition and its future”, Akhil Gupta y James Ferguson (eds.), Anthropological Locations: Boundaries and Grounds of a Field Science, Berkeley, California University Press, 1997: 47-65.

Kuklick, Henrika, "The rise and fall — and potential resurgence- of the comparative method, with special reference to anthropology", Humanities Research, XIV/1 (Canberra, 2007): 51-66.

Kuklick, Henrika, "Personal Equations: Reflections on the History of Fieldwork, with Special Reference to Sociocultural Anthropology", Isis, 102/1 (Chicago, 2011): $1-33$.

Lafone Quevedo, Samuel A., Londres y Catamarca. Cartas a “La Nación”, 1883-84 y 1885, Buenos Aires, Imprenta y Librería de Mayo, 1888. 
Lafone Quevedo, Samuel A., "Nomenclatura Indígena", Revista Patriótica del Pasado Argentino, III (Buenos Aires, 1890): 141-152.

Lafone Quevedo, Samuel A., “On Zemes from Catamarca. A traveler's notes in the Calchaquí region, Argentine Republic”, American Anthropologist, IV (Washington DC, 1891): 356-371.

Lafone Quevedo, Samuel A., "Las lenguas argentinas y el Museo de La Plata". La Nación, XXIII / 6774 (Buenos Aires, 1892a): 1-2.

Lafone Quevedo, Samuel A., "Instrucciones del Museo de La Plata para los colectores de vocabularios indígenas", Revista del Museo de La Plata, III (La Plata, 1892b): 401-416.

Lafone Quevedo, Samuel A., "La Raza Americana de Brinton. Estudio Crítico", Boletín del Instituto Geográfico Argentino, XIV (Buenos Aires, 1893): 505-528.

Lafone Quevedo, Samuel A., "Lenguas Argentinas. Grupo Mataco-Mataguayo del Chaco: Dialecto Vejoz. Vocabulario y Apuntes M.S. D’Orbigny”, Boletín del Instituto Geográfico Argentino, XVII (Buenos Aires, 1896a): 121-176.

Lafone Quevedo, Samuel A., "Los indios Matacos y su lengua. Por el ingeniero Juan Pelleschi, con introducción por Samuel A. Lafone Quevedo M.A.", Boletín del Instituto Geográfico Argentino, XVII (Buenos Aires, 1896b): 559-622.

Lafone Quevedo, Samuel A., "Los indios Matacos y su lengua. Por el P. Joaquín Remedi Ord. Seraf. Misionero Apostólico, con Vocabularios", Boletín del Instituto Geográfico Argentino, XVII (Buenos Aires, 1896c): 331-362.

Lafone Quevedo, Samuel A., Tesoro de Catamarqueñismos. Nombres de lugar y apellidos indios con etimologías y eslabones aislados de la lengua Cacana, Buenos Aires, Imprenta de Pablo Coni, 1898.

Lafone Quevedo, Samuel A., "Progresos de la Etnología en el Río de la Plata durante el año 1898", Boletín del Instituto Geográfico Argentino, XX (Buenos Aires, 1899): 1-64.

Mata de López, Sara Emilia, Tierra y poder en Salta. El Noroeste argentino en vísperas de la independencia, Salta, CEPIHA-Facultad de Humanidades, UNSa, 2005.

Moreno, Francisco P., “A los Americanistas”, Samuel A. Lafone Quevedo, Biblioteca Lingüística del Museo de La Plata. Lenguas Argentinas. Sección del Chaco, Mocoví, La Plata, Taller de Publicaciones del Museo, 1893: iii-v.

Morpurgo Davis, Anna, Nineteenth-Century Linguistics. London: Longman Pearson, 1998.

Museo Mitre, Correspondencia literaria, histórica y política del General Bartolomé Mitre, Buenos Aires, Imprenta de Coni Hermanos, 1912.

Nardi, Ricardo L. J., “El Kakán, lengua de los Diaguitas”, Sapiens, III (Chivilcoy, 1979): 1-33. 
Pegoraro, Andrea S., Las colecciones del Museo Etnográfico de la Universidad de Buenos Aires: un episodio en la historia del americanismo en la Argentina, 18901927, tesis doctoral inédita, FFyL-UBA, 2009.

Podgorny, Irina, "De la antigüedad del hombre en el Plata a la distribución de las antigüedades en el mapa: Los criterios de organización de las colecciones antropológicas del Museo de La Plata entre 1890 y 1930", História, Ciências, SaúdeManguinhos, VI / 1 (Rio de Janeiro, 1999): 81-100.

Podgorny, Irina, "Ser todo y no ser nada: Paleontología y trabajo de campo en la Patagonia a fines del siglo XIX", Sergio Visacovsky y Rosana Guber (comps.), Historias y estilos de trabajo de campo en la Argentina, Buenos Aires, Editorial Antropofagia, 2002: 31-77.

Podgorny, Irina y Lopes, María Margaret, El desierto en una vitrina. Museos e historia natural en la Argentina, 1810-1890, México, Limusa, 2008.

Podgorny, Irina, El sendero del tiempo y de las causas accidentales. Los espacios de la prehistoria en la Argentina, 1850-1910, Rosario, Prohistoria ediciones, 2010.

Poovey, Mary, A History of the Modern Fact: Problems of Knowledge in the Sciences of Wealth and Society, Chicago, University of Chicago Press, 1998.

Rieznik, Marina, Los cielos del sur. Los observatorios astronómicos de Córdoba y de La Plata, 1870-1920, Rosario, Prohistoria ediciones, 2010.

Ross Johnson, Henry Charles, A Long Vacation in the Argentine Alps, or Where to Settle in the River Plate States, London, Richard Bentley Publishers, 1868.

Stocking, George W., After Tylor. British Social Anthropology, 1888-1951, Madison, Wisconsin, The University of Wisconsin Press, 1995.

Torres, Luis María, “Introducción”, Museo Mitre Catálogo razonado de la Sección Lenguas Americanas, tomo I, Buenos Aires, Imprenta de Coni Hermanos, 1909: VII-XLIII.

Vinson, Julien, "Sur l'utilité de rédiger des instructions linguistiques", Bulletins de la Société d'anthropologie de Paris, III (Paris, 1880): 193-196.

White, Ernest William, Cameos from the Silver Land, or the Experiences of a Young Naturalist in the Argentine Republic, London, John van Voorst, 1881-1882.

Whitney, William D., La vie du langage, Paris, Germere Baillière, 1875.

Zubrzycki, Bernarda et al., "La propiedad de la tierra y el agua en Azampay", Carlota Sempé, Susana Salceda, y Marta Maffia (eds.), Azampay. Presente y pasado de un pueblito catamarqueño. Antología de estudios antropológicos, La Plata, Ediciones Al Margen, 2005: 125-141.

Fecha de recepción: 14/10/2010

Fecha de aceptación: 4/07/2011 


\section{Indigenous Languages of Argentina as Objects of Collection. Notes on the Linguistic Studies of Samuel A. Lafone Quevedo at the End of the 19th Century}

This article analyzes the indigenous language classification efforts carried out by Samuel Alexander Lafone Quevedo towards the end of the 19th century, paying special attention to the context of his production. In order to do so, his collection practices, the organization of the linguistic data, the cooperation relationships he established with correspondents and the activities that were carried out in the institutions he was a member of are taken into account.

Key words: Samuel A. Lafone Quevedo (1835-1920); Indigenous languages; Linguistic ethnography; Linguistic data collection; Correspondent networks; Ethno-linguistic maps. 